\title{
Measuring the Reaction of Monetary Policy to the Stock Market ${ }^{1}$
}

\author{
Roberto Rigobon \\ Sloan School of Management, MIT \\ and NBER \\ and \\ Brian Sack \\ Board of Governors of the \\ Federal Reserve System
}

April 19, 2001

\footnotetext{
${ }^{1}$ The authors would like to thank Olivier Blanchard, James Clouse, Rudi Dornbusch, William English, William Nelson, and participants at the Macroeconomics Faculty lunch and the International seminar at MIT for valuable comments. Comments are welcome to bsack@frb.gov or rigobon@mit.edu. The opinions expressed are those of the authors and do not necessarily reflect the views of the Board of Governors of the Federal Reserve System or other members of its staff.
} 


\begin{abstract}
Movements in the stock market can have a significant impact on the macroeconomy and are therefore likely to be an important factor in the determination of monetary policy. However, little is known about the magnitude of the Federal Reserve's reaction to the stock market. One reason is that it difficult to estimate the policy reaction because of the simultaneous response of equity prices to interest rate changes. This paper uses an identification technique based on the heteroskedasticity of stock market returns to identify the reaction of monetary policy to the stock market. The results indicate that monetary policy reacts significantly to stock market movements, with a $5 \%$ rise (fall) in the S\&P 500 index increasing the likelihood of a 25 basis point tightening (easing) by about a half. This reaction is roughly of the magnitude that would be expected from estimates of the impact of stock market movements on aggregate demand. Thus, it appears that the Federal Reserve systematically responds to stock price movements only to the extent warranted by their impact on the macroeconomy.
\end{abstract}

JEL Classification Numbers: E44, E47, E52

Keywords: Monetary Policy, Stock Market, Identification, Heteroskedasticity

Roberto Rigobon

Sloan School of Management

Massachusetts Institute of Technology

50 Memorial Drive, E52-447

Cambridge, MA 02142-1347

and NBER

rigobon@mit.edu
Brian Sack

Division of Monetary Affairs

Federal Reserve Board of Governors

20th and C Streets, Mail Stop 73

Washington, DC 20551

bsack@frb.gov 


\section{Introduction}

In December 1996, Federal Reserve Chairman Alan Greenspan shook global financial markets when he raised the possibility of "irrational exuberance" distorting equity prices. His concern, it appears from the text of his speech, was determining the appropriate monetary policy response in such situations. However, the central bank likely has a broader concern about equity prices, in that equity price movements, through their influence on the macroeconomy, may be an important determinant of the appropriate stance of monetary policy. Indeed, the Chairman mentioned the impact of rising stock prices on household wealth or spending in every single one of his semi-annual testimonies to Congress over the subsequent four years.

This impact of the stock market on the macroeconomy comes primarily through two channels. The first, as suggested by the Chairman's testimonies, is that movements in stock prices influence aggregate consumption through the wealth channel. The total financial wealth of U.S. households stood at over $\$ 35$ trillion as of the end of 1999 , of which over a third was in the form of equity holdings. ${ }^{1}$ More specifically, households are estimated to have had about $\$ 8.5$ trillion of direct equity holdings and another $\$ 5.4$ trillion in indirect holdings of equities, including holdings through mutual funds, life insurance, pension funds, and trusts and estates. Because of the magnitude of these holdings, stock price movements are an important determinant of household wealth. During the run-up in stock prices from 1995 through 1999, capital gains on equity holdings added over $\$ 12.7$ trillion to the wealth of U.S. households. Moreover, the decline in share prices in 2000 lopped over $\$ 2$ trillion off of household financial wealth.

Second, stock price movements can also affect the cost of financing to businesses. In 1999, for example, U.S. non-financial corporations raised a gross amount of $\$ 110$ billion through equity offerings. Higher share prices at that time probably made credit more accessible to various segments of the market, as indicated by the surge in technology-related IPOs realized that year. In addition, firms raised about $\$ 55$ billion in venture capital funds in 1999, which may have also been encouraged by the prospect of high share prices. ${ }^{2}$ As stock prices slumped in the second half of 2000 , the pace of IPOs fell back significantly.

Because of their potential impact on the macroeconomy, stock market movements are likely to be an important determinant of monetary policy decisions. Despite this potential importance, there has been little empirical evidence measuring the magnitude of the Federal Reserve's reaction to the stock market. The primary reason is that it is difficult to empirically estimate the monetary policy reaction due to the simultaneous response of the stock market to policy decisions. Indeed, the policy reaction cannot be identified using traditional approaches for addressing the simultaneity problem, including exclusion restrictions or instrumental variables. For example, it is difficult to

\footnotetext{
${ }^{1}$ The data are taken from the Flow of Funds accounts produced by the Federal Reserve Board. The figures include the equity holdings of non-profit organizations, which are not separated from those of households in the data.

${ }^{2}$ Data on gross equity issuance are from Securities Data Company, while that on venture capital are based on a survey conducted by Venture Economics.
} 
find any instruments that would affect the stock market without being correlated with interest rate movements.

In this paper, we apply a new identification procedure developed by Rigobon (1999) to solve this problem. The identification is based on the heteroskedasticity of shocks to stock market returns. In particular, shifts in the importance of stock market shocks relative to monetary policy shocks, and the estimated changes in the covariance between the shocks that result, allow us to measure the reaction of interest rates to changes in stock market prices. The results suggest that an unexpected increase in the S\&P 500 index by $5 \%$ increases the federal funds rate expected after the next FOMC meeting by about 14 basis points. Translating this into discrete policy moves, a $5 \%$ rise in the S\&P 500 index increases the probability of a 25 basis point tightening by just over a half. ${ }^{3}$ Because the model is symmetric, a $5 \%$ decline in stock prices has similar implications for policy easing.

It is important to note upfront that this result does not imply that the Federal Reserve is targeting stock prices or reacting to perceived misalignments in stock prices. ${ }^{4}$ In fact, Chairman Greenspan has stated that central banks should remain focused on achieving price stability and maximum sustainable growth, suggesting that policymakers should only react to stock prices to the extent that they affect the economic outlook. The findings in this paper are consistent with this view. Using rough calculations, the estimated policy response is approximately of the magnitude needed to offset the expected pass-through of equity market shocks to aggregate demand. Thus, it appears that the Federal Reserve systematically responds to stock price movements only to the extent warranted by their impact on the macroeconomy.

The paper is organized as follows. Section 2 discusses the problem of identification and demonstrates why other widely used identification methods are inappropriate in this context. Section 3 develops the method for identifying the system through stock market heteroskedasticity. Section 4 presents the results and evaluates whether the magnitude of the estimated policy response is sensible. Section 5 investigates the robustness of the results and explores whether the findings could be driven by alternative explanations. Section 6 concludes.

\section{The Endogeneity Problem}

Although movements in the stock market may importantly affect monetary policy decisions, identifying the monetary policy response to the stock market is difficult. The problem is that the stock market endogenously responds to monetary policy decisions at the same time that policy is reacting to the stock market. The simultaneous determination of interest rates and stock prices is depicted in Figure 1. Holding everything else equal, higher interest rates are associated with lower stock

\footnotetext{
${ }^{3}$ That is, if the probability of a policy tightening were $30 \%$ under the existing economic situation, a $5 \%$ rise in stock prices would increase the probability of tightening to $80 \%$. If the probability of an easing were $10 \%$, the rise in stock prices would result in a $40 \%$ chance of tightening.

${ }^{4}$ Cecchetti, Genberg, Lipsky, and Wadhwani (2000) argue that monetary policymakers should react to perceived misalignments in asset prices to reduce the likelihood of asset price bubbles forming.
} 
market prices, given the higher discount rate for the expected stream of dividends. ${ }^{5}$ At the same time, the Federal Reserve may react to higher stock prices by raising interest rates. Realizations of stock prices and interest rates are determined by the intersection of these two schedules and do not provide a clear reading of whether the policy reaction function is upward sloping in stock prices.

The first hint that the endogeneity of the stock market response may be an important consideration comes from the simple correlation between movements in short-term interest rates and the stock market. The correlation between daily changes in the three-month Treasury bill rate and daily changes in the S\&P 500 index, shown later in Figure 3, is typically negative over the period since 1985 - the opposite of the sign that would have been expected from the reaction of monetary policy. ${ }^{6}$

Of course, the correlation between interest rates changes and stock market returns could be influenced by a number of factors. To add more structure, we characterize the dynamic interaction between the stock market and interest rates using a Vector Autoregression (VAR). Assume the dynamics of the short-term interest rate and stock market returns can be written as follows:

$$
\begin{aligned}
i_{t} & =\beta s_{t}+\theta x_{t}+\varepsilon_{t}, \\
s_{t} & =\alpha i_{t}+\phi x_{t}+\eta_{t},
\end{aligned}
$$

where $i_{t}$ is the three-month Treasury bill rate and $s_{t}$ is the daily return on the S\&P 500 index. The data are daily, and the sample runs from March 1985 to December 1999. The variable $x_{t}$ consists of 5 lags of the stock market return and the interest rate, as well as observable macroeconomic shocks. These macroeconomic shocks are measured by the monthly releases of major macroeconomic variables, including the core consumer price index (CPI), the National Association of Purchasing Managers survey (NAPM), non-farm payrolls (NFPAY), the core producer price index (PPI), and retail sales (RETL). Each of these variables are measured by the difference between the released value and the expected value, where those expectations are taken from the Money Market Services survey about a week before the release.

Equation (1) in the VAR can be interpreted as a high frequency policy reaction function for the Federal Reserve. Of course, it is more common to estimate a reaction function using lower frequency data. But the use of daily data is important in this paper because it allows us to more accurately define the heteroskedasticity of the shocks, as will become apparent below. Note that the three-month Treasury bill rate is used in the daily reaction function rather than the federal funds rate. While the federal funds rate is adjusted only every six weeks or so, the three-month Treasury bill rate will adjust daily according to changes in expectations of monetary policy over

\footnotetext{
${ }^{5}$ Of course, the impact on stock prices likely depends on the source of the interest rate movement. On average, however, it appears from the evidence below that higher interest rates cause stock prices to fall.

${ }^{6}$ Note also that the correlation exhibits rich patterns, often becoming positive during periods when the volatility of the stock market increases. These patterns are the basis for the identification procedure used, as discussed shortly.
} 
the near term. ${ }^{7}$ The results therefore infer the magnitude of the monetary policy response to the stock market from market participants' expectations. Equation (2) measures the response of the stock market to the interest rate and other shocks. In the specification, the shock $\varepsilon_{t}$ is a monetary policy shock, and $\eta_{t}$ a shock to S\&P returns.

It is well known that equations (1) and (2) cannot be directly estimated due to the endogeneity of the regressors. Instead, the following reduced form of the system is typically estimated:

$$
\left(\begin{array}{c}
i_{t} \\
s_{t}
\end{array}\right)=\Phi x_{t}+\left(\begin{array}{c}
\nu_{t}^{i} \\
\nu_{t}^{s}
\end{array}\right) .
$$

The parameters of the structural form can sometimes be recovered by imposing restrictions on equations (1) and (2) that allow one to solve for the relevant structural parameters from the covariance matrix of the reduced form residuals. In the macroeconomic literature, these restrictions often take the form of exclusion restrictions - that either $\beta$ or $\alpha$ is zero. However, neither of these restrictions is appropriate in the current context. Obviously, we do not want to set $\beta$ to zero because we are interested in estimating the interest rate response to the stock market.

If we instead assume, inappropriately, that the stock market has no contemporaneous response to the interest rate $(\alpha=0)$, the policy reaction function (1) can be estimated directly. The results from that estimation are shown in Table 1 . The three-month interest rate reacts significantly to several of the macroeconomic news releases. More importantly, however, the estimated response to the stock market, $\beta$, is negative, as the negative correlation shows through to this parameter. The most likely explanation of the perverse sign for the policy response to the stock market is the endogeneity of the stock market response, as highlighted in Figure 1. In that case, the estimated policy reaction is strongly biased.

A more general approach to addressing the endogeneity problem is through instrumental variables. In fact, one could think of the exclusion restriction behind Table 1 as allowing the stock market to instrument for itself. But because the stock prices are likely influenced by the interest rate shock, it is not a valid instrument. More generally, for the U.S. economy it is hard to conceive of any instrument that would affect the stock market without affecting the path of interest rates. Any instrument related to the macroeconomic outlook certainly would not meet this criterion. Even variables that are more closely related to corporate profits, such as earnings surprises, would likely contain information about the macroeconomic outlook as well, and thus be correlated with interest rate changes. ${ }^{8}$ Thus, instrumental variables is unlikely to be an effective approach for addressing the endogeneity problem in this context.

\footnotetext{
${ }^{7}$ More specifically, the three-month bill rate will reflect expectations of federal funds rate changes over the following three months, which will encompass one or two FOMC meetings. Because the liquidity of the Treasury bill has declined over the sample, we have also performed the exercise using eurodollar futures rates. The results, which are discussed in section 5.4, are similar.

${ }^{8}$ More exogenous events such as changes in tax rates on capital gains or corporate profits would also have consequences for monetary policy through their impact on after-tax income.
} 


\section{Table 1: Equation for Daily Changes in Short-Term Interest Rate (Ignoring Endogeneity)}

\begin{tabular}{ccc}
\hline \hline Sample: 1985:3 to 1999:12 & \multicolumn{2}{l}{ Number of obs.: 2733 } \\
Std. dev. of dep. var.: 1.43 & Std. error of estimate: 0.05 \\
R-squared: 0.99 & Durbin-Watson stat.: 2.08 \\
\hline & Impact of 1-SD & T-statistic of \\
Variable & Change (bp) & Coefficient \\
\hline NAPM & 0.10 & 0.53 \\
NFPAY & 3.88 & 8.75 \\
CPI & 1.09 & 1.74 \\
PPI & 0.04 & -0.65 \\
RETL & 1.65 & 3.53 \\
GDP & 0.08 & 0.13 \\
S\&P500 & -0.21 & -1.90 \\
\hline
\end{tabular}

Regressions include a constant and five lags of the interest rate and stock returns.

We would expect such problems to affect a wider class of estimated policy rules as well. For example, a large literature has developed on estimating simple policy rules that describe quarterly movements in the federal funds rate. ${ }^{9}$ One simple variant of these rules is that the federal funds rate responds systematically to the current inflation rate and output gap, but adjusts only slowly from its lagged level, as captured in the following rule:

$$
i_{t}=(1-\rho)\left(\beta_{0}+\beta_{y} y_{t}+\beta_{\pi} \pi_{t}\right)+\rho \cdot i_{t-1},
$$

where $\pi$ is the inflation rate, $y_{t}$ is the output gap, and $i$ is the federal funds rate. ${ }^{10}$ Table 2 shows the estimated parameters from this rule, in which the federal funds rate has significant reactions to both inflation and output, consistent with the findings in the literature. Suppose, however, that the rule were modified to include the change in the S\&P 500 index over the quarter, denoted $\Delta s p 500$, as in:

$$
i_{t}=(1-\rho)\left(\beta_{0}+\beta_{y}\left(Y_{t}-Y^{*}\right)+\beta_{\pi} \pi_{t}+\beta_{s p} \Delta s p 500_{t}\right)+\rho \cdot i_{t-1} .
$$

The change in stock prices may enter the rule because of its impact on the future path of output and inflation, as discussed above. ${ }^{11}$ The estimates from the modified rule indicate that the measured reaction to the stock market is trivial and insignificant, while the other coefficients are largely

\footnotetext{
${ }^{9}$ This literature followed the work of Taylor (1993) and Bryant, Hooper, and Mann (1993). For a collection of papers on monetary policy rules, see the 1999 NBER volume Monetary Policy Rules edited by Taylor.

${ }^{10}$ In the estimated rule, the inflation measure is based on the annual change in the GDP deflator and the output gap is that estimated by the Congressional Budget Office. The federal funds rate is the quarterly average of the effective rate.

${ }^{11}$ It is not evident that the change in stock prices is the appropriate measure to include in a rule determining the interest rate level. An alternative specification was estimated that included the ratio of stock market wealth held by U.S. households to GDP. Under that rule, the policy response to stock market was also insignificant.
} 
unaffected. As in the daily policy rule, the insignificance of the reaction to the stock market may reflect its endogeneity.

Table 2: Quarterly Monetary Policy Rule (Ignoring Endogeneity)

\begin{tabular}{|c|c|c|c|}
\hline Coefficient & $\begin{array}{c}\text { Excluding } \\
\text { Stock Market } \\
(O L S)\end{array}$ & $\begin{array}{c}\text { Including } \\
\text { Stock Market } \\
\text { (OLS) }\end{array}$ & $\begin{array}{c}\text { Including } \\
\text { Stock Market } \\
(I V)\end{array}$ \\
\hline$\beta_{0}$ & $1.13(1.44)$ & $1.14(1.40)$ & $0.98(1.48)$ \\
\hline$\beta_{y}$ & $1.10(6.62)$ & $1.10(6.56)$ & $0.96(7.32)$ \\
\hline$\beta_{\pi}$ & $1.69(2.05)$ & $1.68(2.01)$ & $1.69(2.93)$ \\
\hline$\beta_{s p}$ & - & $-0.00(-0.07)$ & $0.03(0.48)$ \\
\hline$\rho$ & $0.74(12.54)$ & $0.74(13.20)$ & $0.64(6.10)$ \\
\hline
\end{tabular}

T-statistics shown in parenthesis are based on Newey-West standard errors.

Similar findings are reported by Bernanke and Gertler (1999), who estimate a forward-looking policy rule in which the federal funds rate reacts to expectations of inflation and output as well as to the contemporaneous change in stock prices. Their results indicate a negative and insignificant reaction of monetary policy to movements in the stock market. This finding could reflect the forward-looking nature of their rule, as the impact of stock price changes could already be incorporated into the forecasts of output and inflation. However, it may also reflect the endogenous reaction of the stock market to the interest rate. Bernanke and Gertler recognize the simultaneity bias and thus instrument for the change in stock prices with lags of macroeconomic variables and stock returns, but, as discussed above, it is unlikely that these are effective instruments for stock market returns. Indeed, we can use similar instruments in the contemporaneous rule estimated above. The results, also shown in Table 2, again indicate an insignificant response to the stock market.

Overall, the simultaneous equations problem that arises in identifying the VAR in equations (1) and (2) cannot be effectively addressed using exclusion restrictions or instrumental variables. Alternative identification approaches commonly used in the macroeconomics literature, including long-run restrictions or sign restrictions, also do not help with the identification of this parameter. There are no obvious long-run restrictions that could be imposed to separate policy shocks from stock market shocks, as both stock market returns and the interest rate likely revert to some equilibrium values after both types of shocks. Sign restrictions also do not pin down the magnitude of the parameters, as the observed correlation could be explained under larger (or smaller) policy responses as long as the endogenous response to the stock market were also larger (or smaller). Given the shortcomings of commonly-used identification techniques, we instead use a methodology based on the heteroskedasticity of the error terms to identify the monetary policy reaction to the stock market, as described in the next section. 


\section{Identification through Heteroskedasticity}

The above discussion indicates that identification approaches that have been widely used in the macroeconomics literature cannot appropriately separate the response of monetary policy to the stock market from the endogenous reaction of the stock market to interest rates. In this section, we expand the procedure developed by Rigobon (1999) which uses the heteroskedasticity found in interest rates and stock market returns to identify the reaction of monetary policy to the stock market.

The identification relies on the following observation: The responsiveness of monetary policy will become a stronger determinant of the covariance between interest rates and stock market returns during periods when equity market shocks are more variable. To see this, consider what happens if the variance of the stock market shocks rises while the variance of the monetary policy shocks remains unchanged. Such a shift causes the realizations of stock market returns and interest rates to more closely trace out the policy reaction function than before, as shown in Figure 2. In other words, the disturbances are distributed around an ellipse that enlarges along the policy reaction function when the shocks to the stock market are more volatile. Thus, we are able to identify the slope of the policy reaction function based on changes in the covariance of interest rate and stock market movements across periods when the variance of their shocks shifts.

A rough glance at the data suggests that shifts in the volatility of shocks do in fact affect the correlation between changes in interest rates and stock prices. Figure 3 shows the six-month rolling correlation between daily changes in the three-month Treasury bill rate and daily changes in the S\&P 500 index. As noted earlier, this correlation is typically negative, likely reflecting the endogenous response of stock prices to the interest rate (the downward-sloping schedule in Figure 2). However, the correlation varies fairly extensively over time. In fact, the correlation often becomes positive during periods in which the volatility of stock market changes is elevated. Under many distributions such as the bivariate normal, the correlation between the shocks would vary with shifts in the variance of the shocks, but it would not shift signs. Such shifts are most likely explained by a shift in the relative importance of different shocks, as depicted in Figures 1 and 2.

In the empirical exercise that follows, we want to allow for a more generalized specification than depicted in Figure 2. In particular, we modify the VAR used above to include unobserved shocks that affect both stock returns and interest rates and that may also be heteroskedastic. In that

case, the dynamic structural equations for the stock market and the short-term interest rates can be written as follows:

$$
\begin{aligned}
i_{t} & =\beta s_{t}+\theta x_{t}+\gamma z_{t}+\varepsilon_{t}, \\
s_{t} & =\alpha i_{t}+\phi x_{t}+z_{t}+\eta_{t},
\end{aligned}
$$

where (6) is the monetary policy reaction function and (7) is the stock market equation. These 
equations are similar to equations (1) and (2) above, except we have included an additional variable $z_{t}$ that represents the unobservable shocks (with the coefficient on $z_{t}$ in the stock market equation normalized to 1 ). The variable $z_{t}$ could capture changes in risk preferences, liquidity shocks, or macroeconomic shocks other than those captured by $x_{t}$. As before, we assume that $\varepsilon_{t}$ and $\eta_{t}$, the policy and stock market shocks, respectively, are orthogonal. However, this assumption is not very restrictive, as the presence of the unobserved shock $z_{t}$ can account for correlation across the structural disturbances.

Generalizing the specification to include unobservable shocks comes at some cost. In particular, instead of having full identification of the system, we would only be able to achieve partial identification. But the partial identification will be sufficient to measure the reponse of monetary policy to the stock market - the focus of this paper. Moreover, as we show below, the presence of $z_{t}$ is crucial for properly measuring the policy reaction, and we can reject the specification in which common shocks are not included.

The parameter of interest is $\beta$ - the reaction of the short-term interest rate to the stock market. However, equation (6) cannot be estimated directly, because of the simultaneity problem discussed above, and because $z_{t}$ is unobserved. In fact, only the following reduced form of this system can be estimated:

$$
\left(\begin{array}{c}
i_{t} \\
s_{t}
\end{array}\right)=\Phi x_{t}+\left(\begin{array}{c}
\nu_{t}^{i} \\
\nu_{t}^{s}
\end{array}\right)
$$

where the reduced form residuals $\left(\nu_{t}^{i}\right.$ and $\left.\nu_{t}^{s}\right)$ are given by

$$
\begin{aligned}
\nu_{t}^{i} & =\frac{1}{1-\alpha \beta}\left[(\beta+\gamma) z_{t}+\beta \eta_{t}+\varepsilon_{t}\right], \\
\nu_{t}^{s} & =\frac{1}{1-\alpha \beta}\left[(1+\alpha \gamma) z_{t}+\eta_{t}+\alpha \varepsilon_{t}\right]
\end{aligned}
$$

These reduced form innovations have the following covariance matrix:

$$
\Omega=\frac{1}{(1-\alpha \beta)^{2}}\left[\begin{array}{cc}
(\beta+\gamma)^{2} \sigma_{z}^{2}+\beta^{2} \sigma_{\eta}^{2}+\sigma_{\varepsilon}^{2} & (1+\alpha \gamma)(\beta+\gamma) \sigma_{z}^{2}+\beta \sigma_{\eta}^{2}+\alpha \sigma_{\varepsilon}^{2} \\
\cdot & (1+\alpha \gamma)^{2} \sigma_{z}^{2}+\sigma_{\eta}^{2}+\alpha^{2} \sigma_{\varepsilon}^{2}
\end{array}\right]
$$

The problem of identification is that the covariance matrix only provides three equations - two variances and a covariance - while there are six unknowns: $\alpha, \beta, \gamma, \sigma_{z}^{2}, \sigma_{\eta}^{2}$, and $\sigma_{\varepsilon}^{2}$.

It is unlikely that this covariance matrix remains constant over the sample, though. Indeed, a prevalent characteristic of macroeconomic and financial data is heteroskedasticity. Both interest rates and stock market returns are known to exhibit patterns of volatility that are somewhat predictable, including periods during which their variances are elevated. While such heteroskedasticity is typically ignored in VAR studies, here we use it to our advantage to appropriately identify the 
parameter $\beta .^{12}$

The approach follows the technique developed by Rigobon (1999), who noted that the presence of unconditional heteroskedasticity in the reduced form innovations provides additional equations to the system represented by (9). Consider, for example, the impact of a shift to a regime with a different covariance matrix. In this case, the new regime provides three new equations (the covariance matrix). Of course, without any restrictions the new regime also adds three new unknown parameters - the parameters $\sigma_{z}^{2}, \sigma_{\eta}^{2}$, and $\sigma_{\varepsilon}^{2}$ under the new regime. But allowing for heteroskedasticity will help identify the system if additional assumptions can be imposed on the variances of the shock processes. Assumptions of this type may be more appropriate than the exclusion restrictions considered above.

In the current context, we assume that the monetary policy shocks $\varepsilon_{t}$ are homoskedastic. This assumption is not very restrictive, given the richness of the specification of the policy reaction function. In particular, this assumption does not imply that the interest rate itself is homoskedastic. On the contrary, the interest rate still exhibits heteroskedasticity that is driven by the systematic response to equity market shocks and by the heteroskedasticity of the unobserved common shocks. Under the assumption of homoskedastic policy shocks, a shift in the covariance matrix adds three equations but only two unknown parameters.

In that case, the parameter $\beta$ is identified as long as there are at least three different regimes for the covariance matrix. (The results below suggest that there are at least three regimes.) To highlight the solution to the identification problem, assume there are three regimes in the covariance matrix. Then, for $i=1,2,3$ the covariance matrix can be written as

$$
\Omega_{i}=\frac{1}{(1-\alpha \beta)^{2}}\left[\begin{array}{cc}
(\beta+\gamma)^{2} \sigma_{i, z}^{2}+\beta^{2} \sigma_{i, \eta}^{2}+\sigma_{\varepsilon}^{2} & (1+\alpha \gamma)(\beta+\gamma) \sigma_{i, z}^{2}+\beta \sigma_{i, \eta}^{2}+\alpha \sigma_{\varepsilon}^{2} \\
\cdot & (1+\alpha \gamma)^{2} \sigma_{i, z}^{2}+\sigma_{i, \eta}^{2}+\alpha^{2} \sigma_{\varepsilon}^{2}
\end{array}\right]
$$

Two important assumptions have been made in equation (10). First, as indicated above, the variance of the Fed's reaction function remains constant across regimes. Second, we have assumed that the parameters $(\alpha, \beta$, and $\gamma)$ are stable across the covariance regimes. Note that this second assumption is implicitly made in the vast majority of related empirical studies. In the macroeconomics literature, VARs are often estimated across samples that surely exhibit heteroskedasticity, without allowing shifts in parameters. Similarly, in the finance literature, many studies that even explicitly allow for variation in volatility, including GARCH models, often impose that the parameters of the underlying equation are fixed.

Under these assumptions, the identification is straightforward. Define $\Delta \Omega_{21}=\Omega_{2}-\Omega_{1}$ and

\footnotetext{
${ }^{12}$ In the present paper we concentrate only on identification under unconditional heteroskedasticity. Identification under conditional heteroskedasticity can also be solved using the same arguments.
} 
$\Delta \Omega_{31}=\Omega_{3}-\Omega_{1}$. Equation (10) implies that

$$
\Delta \Omega_{j 1}=\frac{1}{(1-\alpha \beta)^{2}}\left[\begin{array}{cc}
(\beta+\gamma)^{2} \Delta \sigma_{j 1, z}^{2}+\beta^{2} \Delta \sigma_{j 1, \eta}^{2} & (1+\alpha \gamma)(\beta+\gamma) \Delta \sigma_{j 1, z}^{2}+\beta \Delta \sigma_{j 1, \eta}^{2} \\
\cdot & (1+\alpha \gamma)^{2} \Delta \sigma_{j 1, z}^{2}+\Delta \sigma_{j 1, \eta}^{2}
\end{array}\right]
$$

where $\Delta \sigma_{j 1, z}^{2}=\sigma_{j, z}^{2}-\sigma_{1, z}^{2}$ and $\Delta \sigma_{j 1, \eta}^{2}=\sigma_{j, \eta}^{2}-\sigma_{1, \eta}^{2}$ for $j=\{2,3\}$. Because the parameters are stable and $\sigma_{\varepsilon}^{2}$ is homoskedastic, the change in the covariance matrix does not depends on the variance of the monetary policy shocks.

These two changes in the covariance matrices form a system of six nonlinear equations with seven unknowns, but in which $\beta$ is just identified. To see this, rewrite the covariance matrix as:

$$
\Delta \Omega_{j 1}=\frac{1}{(1-\alpha \beta)^{2}}\left[\begin{array}{cc}
\omega_{z, j}+\beta^{2} \Delta \sigma_{j 1, \eta}^{2} & \theta \omega_{z, 2}+\beta \Delta \sigma_{j 1, \eta}^{2} \\
\cdot & \theta^{2} \omega_{z, 2}+\Delta \sigma_{j 1, \eta}^{2}
\end{array}\right]
$$

where

$$
\begin{aligned}
\theta & =\frac{1+\alpha \gamma}{\beta+\gamma} \\
\omega_{z, j} & =(\beta+\gamma)^{2} \Delta \sigma_{j 1, z}^{2} .
\end{aligned}
$$

The six equations that result can be written as follows:

$$
\begin{aligned}
\omega_{z, 2}+\beta^{2} \Delta \sigma_{21, \eta}^{2} & =(1-\alpha \beta)^{2} \cdot \Delta \Omega_{21,11} \\
\theta \omega_{z, 2}+\beta \Delta \sigma_{21, \eta}^{2} & =(1-\alpha \beta)^{2} \cdot \Delta \Omega_{21,12} \\
\theta^{2} \omega_{z, 2}+\Delta \sigma_{21, \eta}^{2} & =(1-\alpha \beta)^{2} \cdot \Delta \Omega_{21,22} \\
\omega_{z, 3}+\beta^{2} \Delta \sigma_{31, \eta}^{2} & =(1-\alpha \beta)^{2} \cdot \Delta \Omega_{31,11} \\
\theta \omega_{z, 3}+\beta \Delta \sigma_{31, \eta}^{2} & =(1-\alpha \beta)^{2} \cdot \Delta \Omega_{31,12} \\
\theta^{2} \omega_{z, 3}+\Delta \sigma_{31, \eta}^{2} & =(1-\alpha \beta)^{2} \cdot \Delta \Omega_{31,22}
\end{aligned}
$$

where $\Delta \Omega_{j 1, k l}$ is the $k$ and $l$ element of the $j$ matrix. If $\theta \beta \neq 1$, which assures finite variance, then the three equations for each covariance matrix collapse to

$$
\begin{aligned}
& \theta=\frac{\Delta \Omega_{21,12}-\beta \Delta \Omega_{21,22}}{\Delta \Omega_{21,11}-\beta \Delta \Omega_{21,12}} \\
& \theta=\frac{\Delta \Omega_{31,12}-\beta \Delta \Omega_{31,22}}{\Delta \Omega_{31,11}-\beta \Delta \Omega_{31,12}},
\end{aligned}
$$

which is a system of two equations with two unknowns. Finally, equations (11) and (12) imply a 
quadratic equation for $\beta$ :

$$
a \beta^{2}-b \beta+c=0
$$

where

$$
\begin{aligned}
a & =\Delta \Omega_{31,22} \Delta \Omega_{21,12}-\Delta \Omega_{21,22} \Delta \Omega_{31,12} \\
b & =\Delta \Omega_{31,22} \Delta \Omega_{21,11}-\Delta \Omega_{21,22} \Delta \Omega_{31,11} \\
c & =\Delta \Omega_{31,12} \Delta \Omega_{21,11}-\Delta \Omega_{21,12} \Delta \Omega_{31,11} .
\end{aligned}
$$

If the quadratic equation has a real solution, the system of equations is identified and can be solved for $\beta$ and $\theta$. It is easy to show that one of the solutions of the system of equations gives the true values, while the second solution gives their inverse. ${ }^{13}$ Moreover, it is easy to show that, at least theoretically, because the covariance matrices are positive definite, there should be always a real solution to the quadratic equation.

Note that when there are more than three regimes for the covariance matrix, any three can be used to arrive at two equations like (11) and (12). If all of the assumptions of the model hold, the estimate of $\beta$ should be the same under any subset of three regimes. In the empirical implementation, we use this as a test of overidentifying restrictions. A rejection that the coefficient estimates are the same could indicate that the parameters are unstable across regimes, that the homoskedasticity assumption on the policy equation is violated, or that there are non-linearities that are not captured in our specification. The test is described in more detail below.

\section{Results}

The initial step in the estimation procedure is to determine the different regimes for the variancecovariance matrix of the reduced form shocks to monetary policy and the stock market. To do so, we begin by estimating the reduced form (8) and computing the residuals. As expected, there are rich patterns to the volatility of the shocks to stock market returns and the short-term interest rate. Because the periods of elevated volatility for interest rates and the stock market at times coincide with one another and at other times do not, we define four regimes: one in which both interest rates and stock returns have low variance, one in which they both have high variance, and two in which one has high and the other low variance. Periods of high variance are defined as when the thirty-day rolling variance of the residual is more than one standard deviation above its average. The four covariance regimes that result are described in Table 3. As shown in the table,

\footnotetext{
${ }^{13}$ The quadratic equation has two solutions. One corresponds to the values of $\theta$ and $\beta$ from the system of equations (6) and (7). The other corresponds to a system of equations in which the stock market reaction equation is written in terms of the interest rate and the policy reacton equation in terms of stock prices. In that case, the solution gives the values for $\theta^{*}=1 / \beta$ and $\beta^{*}=1 / \theta$.
} 
the covariance between these variables tends to fluctuate with the movements in their variances, often becoming positive as the variance of the stock market increases.

Table 3: Regimes for Variance-Covariance Matrix

\begin{tabular}{lcccc}
\hline \hline & $\begin{array}{c}\text { Variance of } \\
\text { Policy Shocks }\end{array}$ & $\begin{array}{c}\text { Variance of } \\
\text { Stk Mkt Shocks }\end{array}$ & $\begin{array}{c}\text { Frequency } \\
\text { Covariance }\end{array}$ & of Obs. \\
\hline Regime 1 & 0.00226 & 0.5238 & -0.00262 & $90.2 \%$ \\
Regime 2 & 0.00374 & $\mathbf{2 . 4 7 3 2}$ & 0.02757 & $3.1 \%$ \\
Regime 3 & $\mathbf{0 . 0 2 3 2 6}$ & $\mathbf{4 . 5 4 2 2}$ & 0.03907 & $2.6 \%$ \\
Regime 4 & $\mathbf{0 . 0 1 0 5 9}$ & 0.4659 & -0.02462 & $4.1 \%$ \\
\hline
\end{tabular}

High variance regimes are in bold. All variables are measured in percentage points.

This approach for defining the different regimes of the variance-covariance matrix is admittedly arbitrary. However, the estimates are consistent even if the heteroskedasticity is misspecified, as long as the true data exhibits heteroskedasticity and the regimes are not misspecified too badly. As demonstrated in section 5, because the covariance matrices of misspecified regimes are linear combinations of the true covariance matrices, the system of equations obtained from the mispecified system has the same solution as those derived from a more well specified set of regimes. The only case in which the estimates are not consistent is if the regimes are specified so poorly that each regime contains the same weightings of the true underlying regimes. Some direct evidence on the impact of misspecifying the heteroskedasticity is also presented in section 5 .

The analysis from the previous section indicated that the monetary policy reaction to the stock market - $\beta$ in equation (6) — could be identified as long as there were three regimes for the covariance matrix. We first estimate the reaction coefficient using the first three regimes listed in Table 3 . The results indicate a positive policy response to the stock market, with an estimated coefficient $\beta$ of 0.02139. The distribution of the coefficient can be calculated by bootstrap and is shown in Figure 4 (top panel). In implementing the bootstrap, we use the asymptotic distribution of the covariance matrices and solve for the estimated coefficient in 1000 draws. As apparent from the figure, the estimated parameter is strongly significant, with none of the calculated distribution falling below zero.

This is the major result of the paper: By employing a more appropriate identification approach based on heteroskedasticity, we find a significant positive reaction of monetary policy to the stock market. The point estimate for the response coefficient $\beta$ indicates that a $5 \%$ rise in the S\&P 500 index tends to increase the three-month interest rate by 10.7 basis points. It may be useful to translate this estimate into the probability of a policy tightening. On average, the next FOMC meeting will be about three weeks away, and the three-month rate reflects the expected rate to prevail over the next twelve weeks. Thus, only $3 / 4$ of the expected impact on the federal funds rate shows up in the three-month interest rate on impact. The estimated coefficient therefore 
corresponds roughly to an increase in the expected federal funds rate of 14.3 basis points (equal to 10.7 times 4/3). Translating this into discrete policy actions, a 5\% rise in the S\&P 500 index increases the probability of a 25 basis point tightening by about $57 \%$. A similar-sized fall in stock prices would have the same implications for a 25 -basis point easing.

Similar results are obtained if the parameter is estimated from other subsets of regimes. As was shown above, the parameter $\beta$ is just identified with three regimes and is overidentified when there are four. Indeed, we can instead estimate $\beta$ using any three regimes, such as regimes 1,2 , and 4 . The point estimate resulting from that subset of regimes is 0.02105 , and the distribution of the estimate is shown in Figure 4 (bottom panel). The estimate is again significantly positive, with no realizations falling below zero, and its magnitude is very similar to the previous estimate.

Table 4: Estimates under Alternative Subsets of Regimes

\begin{tabular}{lccccc}
\hline \hline & Regimes & Regimes & Regimes & Regimes & Regimes \\
& $1,2,3$ & $1,2,4$ & $1,3,4$ & $2,3,4$ & All \\
\hline Mean of distribution & 0.021386 & 0.021051 & 0.027292 & 0.14024 & 0.021022 \\
Std. dev. of distribution & 0.005822 & 0.005229 & 0.31368 & 3.812253 & 0.005229 \\
Median of distribution & 0.021168 & 0.020849 & 0.016886 & 0.01913 & 0.020849 \\
Mass below zero & $0.0 \%$ & $0.0 \%$ & $1.4 \%$ & $1.4 \%$ & $0.0 \%$ \\
\hline
\end{tabular}

The estimates resulting from all four possible subsets of regimes are summarized in Table 4. As can be seen, the estimates from the subsets shown in Figure 4 are very close to one another. The other two subsets of regimes yield estimates that are much less precise. The standard deviation of these estimates blows up considerably, primarily because of some realizations with very high values. However, even in those cases only a small mass of observations falls below zero, and the medians of the distributions are very close to the other estimates. Table 4 also shows the results obtained if all four regimes are used to estimate $\beta$. In this case, we treat equations (11) and (12) as moment conditions and solve for the parameters using GMM. The resulting estimates are very similar to those from the subsets of regimes shown in Figure 4.

As previously mentioned, the difference between estimates under the various subsets of regimes can be used as a test of overidentifying restrictions. Such a test would indicate whether the restrictions imposed on the model, most notably the assumption that the parameters are stable across different regimes and the homoskedasticity assumption of the policy shocks, can be rejected. Note, however, that this approach does not test the assumption that the three shocks are uncorrelated. Because there are five estimates available, many different overidentification tests could be performed. We focus first on the estimates from using regimes 1,2 , and 3 and regimes 1,2 , and 4 . The distribution of the difference in the estimates, which is also computed using the same bootstrap as before, is shown in Figure 5. According to that distribution, $61.8 \%$ of the observations are negative and $38.2 \%$ positive, which implies that we cannot reject the hypothesis that the estimates are 
the same. In other words, the overidentifying restrictions are easily passed. Moreover, additional tests indicate that the overidentifying restrictions could not be rejected using any subset of the five estimates. ${ }^{14}$

The empirical exercise in this paper is concerned only with measuring the policy reaction to the stock market, and not with determining whether such a reaction is optimal. Nevertheless, it may be useful to assess whether the magnitude of the estimated policy reaction is reasonable from a macroeconomic perspective. To do so, we compare the estimated reaction to two benchmarks. The first is based on a rough calculation of the impact of stock price movements on aggregate spending. As previously indicated, there are several channels through which the stock market affects the economy, including the wealth effect on aggregate consumption, and the cost of financing channel for investment. For simplicity, we will focus only on the first of these, realizing that we could be underestimating the expected impact.

If equity prices were to broadly rise by $5 \%$, for example, household wealth would increase by about $\$ 695$ billion, based on household equity holdings as of the end of 1999 . If the marginal propensity to consume out of stock market wealth is $4 \%$, then aggregate consumption would rise by $\$ 28$ billion, pushing up GDP by about $0.30 \% .{ }^{15}$ To map this change into a movement in the federal funds rate, we rely on the literature on estimated monetary policy rules. A vast number of papers, initiated by Taylor (1993) and others, have estimated policy rules in which the federal funds rate reacts to output and inflation. While Taylor wrote down a monetary policy reaction coefficient of 0.5 to the output gap, other papers have estimated this coefficient to be higher, perhaps around 1 (as in the estimated rule presented in Table 2). ${ }^{16}$ Under that range of estimates, a $5 \%$ rise in the equity market, through its expected impact on the output gap, would be expected to result in a 15 to 30 basis point rise in the federal funds rate.

Of course, there are a number of reasons to take this back-of-the-envelope calculation with caution. We ignored other channels through which the stock market impacts the economy as well as any multiplier effects. Moreover, the calculation does not account for dynamics. Stock market wealth has an impact on spending only after a considerable lag, although policy makers may still choose to react immediately given the lags in the impact of monetary policy. Despite these possible complications, the calculation suggests that the magnitude of the estimated policy reaction to the stock market is in the ballpark of the reaction that would be expected if the Federal Reserve were concerned only with the ultimate impact of the stock market on output and inflation.

A second benchmark for gauging the magnitude of the policy reaction relies on the Federal Reserve's model of the U.S. economy. The model, which is described in Reifschneider, Tetlow, and

\footnotetext{
${ }^{14}$ All tests of overidentification restrictions were computed by evaluating the mass below zero of the difference in the estimates.

${ }^{15}$ For estimates of the impact of stock price changes on aggregate consumption, see Poterba and Samwick (1995), among others.

${ }^{16}$ See, for example, Clarida, Gali, and Gertler (2000), Judd and Rudebusch (1998), and Sack (1998), among many others.
} 
Williams (1999), provides an estimate of the extent to which changes in stock market wealth feed through into aggregate demand. In that paper, the authors presents the simulated response of the economy to a permanent shock to the equity risk premium, which affects stock prices without having a direct effect on other macroeconomic variables. Under a fixed real federal funds rate, the shock would stimulate aggregate demand and lead to a rise in inflation. Because of these effects, though, the central bank would likely tighten in response to the shock. Indeed, the authors consider the response of the economy under a "stabilizing policy" - one that effectively reduces the impact

of the shock on output and inflation. Judging from the path of the policy rate under the stabilizing policy, it appears that a permanent $5 \%$ shock to the value of the stock market warrants a persistent response of the federal funds rate of about 12.5 basis points.

These two benchmarks suggest that one would expect a positive reaction of monetary policy to the stock market, consistent with our finding of a significant, positive response coefficient. Moreover, both of these benchmarks indicate that the estimated policy response coefficient is within a reasonable range of the magnitude that one would have expected for a central bank concerned only with the macroeconomic activity.

\section{Robustness}

In this section, several sensitivity exercises are run to evaluate the robustness of the specification we have used. In short, the findings are that the results are largely robust to misspecification of the heteroskedasticity of the shocks, but that the inclusion of the unobserved common shock has a considerable impact on the results.

\subsection{The presence of common shocks}

The specification above included a common shock $z_{t}$ that could capture a number of factors affecting the stock market and interest rates. One possibility is that these shocks represent shifts in investor risk preferences, which could induce positive correlation between changes in stock prices and in interest rates. A reduction in risk tolerance, for example, could generate a flight-to-safety effect in which investors shift out of stocks and into Treasury bills, pushing down both stock prices and interest rates. Thus, the inclusion of these shocks in the specification is important, because otherwise it could be argued that the positive coefficient obtained in the estimation reflects shifts in risk preferences rather than the policy response to the stock market.

In the absence of a common shock, the specification is as follows:

$$
\begin{aligned}
i_{t} & =\beta s_{t}+\theta x_{t}+\varepsilon_{t}, \\
s_{t} & =\alpha i_{t}+\phi x_{t}+\eta_{t},
\end{aligned}
$$

where the assumptions are as before. Given that $\varepsilon_{t}$ and $\eta_{t}$ are independent and that $\alpha$ is presumably 
negative, the coefficient $\beta$ is forced to capture the positive correlation induced by the common shock. This will cause an upward bias in the estimation of $\beta$, if there in fact is a common shock that is excluded (and $\gamma$ is positive). From the reduced form, the covariance matrix of the residuals is

$$
\Omega=\frac{1}{(1-\alpha \beta)^{2}}\left[\begin{array}{cc}
\beta^{2} \sigma_{\eta}^{2}+\sigma_{\varepsilon}^{2} & \beta \sigma_{\eta}^{2}+\alpha \sigma_{\varepsilon}^{2} \\
. & \sigma_{\eta}^{2}+\alpha^{2} \sigma_{\varepsilon}^{2}
\end{array}\right] .
$$

As before, we solve the problem of identification by using the additional equations provided by the heteroskedasticity of the data. In the case with no common shock, however, only two regimes are enough to identify the system of equations. Moreover, it is not necessary to assume that the variance of $\varepsilon_{t}$ is constant, and thus we do not impose it in the estimation.

The procedure for estimating $\beta$ is similar to that of section 4. The VAR is first estimated to recover the reduced form residuals. Four regimes are defined to capture shifts in the covariance matrix, using the same procedure as above. Using only two of the regimes, we solve the system of six equations for the parameter $\beta{ }^{17}$ As before, because of small sample issues in the estimation of covariance matrices, we use bootstrapping to compute the distribution of the estimates and the differences between estimates.

We begin by estimating $\beta$ under equations (13) and (14) using the first and third regimes. The resulting distribution, shown in Figure 6 (top panel), has a mean of 0.140772 . The estimate is significantly positive, with $1.0 \%$ of the realizations below zero. More importantly, notice that the estimate (comparing the means) is more than six times larger than the estimates obtained in the previous section. This difference is consistent with the intuition expressed earlier - that the exclusion of the common shock could bias upward the coefficient. The potential bias is particularly problematic in this case, in which the first and the third regimes are used to derive the estimate. The third regime, because it involves a high variance of both the interest rate and the stock market, could be driven by a change in the variance of the common shock, thus resulting in a larger bias.

If the parameter $\beta$ is instead estimated using the first and second regimes, the results are much different. As seen in Figure 6 (lower panel), the point estimate is 0.022922 , and none of the mass of the distribution is below zero. This estimate is close to the estimates from the previous section, which is perhaps not surprising given the following intuition. The second regime is the one in which only the variance of the stock market increases while the variance of the interest rate remains largely unchanged. Even if the true model has common shocks, this regime shift is unlikely to be explained by an increase in the variance of the common shock. Therefore, most of the variation in the second moments is probably generated from a shift in the variance of the stock market shock, so that the estimate of $\beta$ should be close to that found in the previous section. Of course, we can derive an estimate of $\beta$ from any subset of two regimes, allowing for 12 different estimates, or by using all of the regimes. In Table 5, for brevity, we report only a subset of the estimates. As can be seen,

\footnotetext{
${ }^{17}$ We have excluded the algebra showing the solution for the parameter $\beta$ in the bivariate case in order to conserve space. More details about the solution can be obtained from the authors upon request.
} 
these estimates show considerable variation across the choice of regimes, and some of them have considerable mass below zero.

Table 5: Estimates under Alternative Subsets of Regimes

\begin{tabular}{lcccc}
\hline \hline & Regimes & Regimes & Regimes & Regimes \\
& 1,2 & 1,3 & 1,4 & All \\
\hline Mean of distribution & 0.022923 & 0.140772 & 0.035265 & 0.001715 \\
Std. dev. of distribution & 0.005678 & 0.375107 & 0.621873 & 0.002106 \\
Median of distribution & 0.02268 & 0.091136 & 0.001987 & 0.002021 \\
Mass below zero & $0.0 \%$ & $1.0 \%$ & $22.6 \%$ & $18.0 \%$ \\
\hline
\end{tabular}

As in the previous section, a test of overidentifying restrictions can be carried out by comparing the estimates of $\beta$ under any two different sets of regimes. We again focus on only two estimates in order to conserve space. ${ }^{18}$ Under the assumption that equations (13) and (14) are the correct description of the data, both estimates should be the same. In that case, changes in the correlation between the interest rate and the stock market are fully explained by $\beta$ and $\alpha$ and the changes in the variances of the structural shocks. This imposes an internal consistency across the different regimes that is testable. On the other hand, if there exists a common shock not included in the specification, the correlation is also affected by shifts in its variance and the relative responsiveness of stock prices and interest rates to the shock. Thus, a richer set of changes in the covariance matrix can be realized, and it will be impossible to match all of the covariance matrices with a constant $\alpha$ and $\beta$.

The distribution of the difference in the two estimates of $\beta$ is shown in Figure 7. The mass of the distribution below zero is only $4.9 \%$, indicating a rejection of the hypothesis that the estimates are the same. ${ }^{19}$ Thus, the assumptions underlying the model in equations (13) and (14) fail the test of overidentifying restrictions. Recall that a similar test from the previous section could not reject the assumptions behind the specification that included a common shock (with $38 \%$ of the mass of the distribution spanning zero). The tests are based on the exact same draws of the covariance matrices, so that the rejection has to do strictly with whether the common shock is included. Additionally, the rejection in this section shows that the test has some power in this data, giving more credence to the lack of rejection in the previous section.

The inclusion of the common shock is therefore crucial for arriving at an accurate estimate of the policy response $\beta$. As discussed, a likely explanation of this shock is a shift in investor risk preferences, which appear to generate large movements in asset prices at times, including occasional

\footnotetext{
${ }^{18}$ Based on just the 12 potential estimates of $\beta$ using combinations of two regimes, there are 66 possible tests of overidentifying restrictions.

${ }^{19}$ Even stronger rejections of the test of overidentifying restrictions are obtained using other subsets of regimes. For example, the distribution of the difference in the estimates from regimes 1-2 and 1-4 has a mass below zero of $99.7 \%$.
} 
flight-to-safety episodes. Stock prices typically fall during those episodes, and short-term Treasury rates can decline from safe-haven buying that is unrelated to policy expectations. ${ }^{20}$ However, the model without common shocks would attribute all of these positive comovements to policy expectations, thus resulting in a very large estimated response coefficient. However, the common shock does not necessarily have to be given this interpretation. The empirical exercise is agnostic about the source of the common shocks. Indeed, the model with a common shock is equivalent to a model with no common shock but where we allow the structural shocks to be correlated. In that case, an increase in the variance of $z_{t}$ is equivalent to a shift in both the variance and the covariance of the structural shocks. The empirical exercise does indicate, however, that the model is misspecified if the common shocks are excluded.

\subsection{Heteroskedasticity misspecification}

As was mentioned briefly in section 4, the estimates are consistent even under some misspecification of the heteroskedasticity. Taking the reduced form innovations from our specification, equations (6) and (7) can be expressed as

$$
\left(\begin{array}{c}
\nu_{t}^{i} \\
\nu_{t}^{s}
\end{array}\right) A^{\prime}=z_{t} \Gamma^{\prime}+\left(\begin{array}{c}
\varepsilon_{t} \\
\eta_{t}
\end{array}\right)
$$

where A includes the parameters measuring the contemporaneous reactions of the variables and $\Gamma=\left(\begin{array}{l}\gamma \\ 1\end{array}\right) \cdot{ }^{21}$ In the identification procedure with three regimes for the variance-covariance matrix of reduced form innovations, we solve the following system of equations:

$$
\left[\begin{array}{l}
\Omega_{i, s}^{r e g 1} \\
\Omega_{i, s}^{r e g 2} \\
\Omega_{i, s}^{r e g} 3
\end{array}\right]=A^{-1} \Gamma\left[\begin{array}{c}
\sigma_{z}^{r e g 1} \\
\sigma_{z}^{r e g 2} \\
\sigma_{z}^{r e g 3}
\end{array}\right] \Gamma^{\prime} A^{\prime}-1+A^{-1}\left[\begin{array}{c}
\Omega_{\varepsilon, \eta}^{r e g} 1 \\
\Omega_{\varepsilon, \eta}^{r e g 2} \\
\Omega_{\varepsilon, \eta}^{r e g 3}
\end{array}\right] A^{\prime-1},
$$

where $\Omega_{i, s}^{r e g j}$ is the covariance matrix between the reduced form shocks in regime $j$. Similarly, $\Omega_{\varepsilon, \eta}^{r e g j}$ is the covariance matrix of the structural shocks, and $\sigma_{z}^{r e g j}$ is the variance of the common shock. We assume that the system of equations has a solution, or implicitly that it satisfies a rank condition. ${ }^{22}$

If the regimes are misspecified, then the computed covariance matrices are linear combinations of the true covariance matrices. Formally, the misspecified covariance matrix of regime $j$ can be

\footnotetext{
${ }^{20}$ While flight-to-safety episodes can push down a variety of short-term interest rates, Treasury yields may be particularly prone to such effects. We estimated an alternative specification that used a eurodollar futures rate instead of the Treasury bill rate. The results were similar: the estimated policy response is positive and significant, although a bit smaller, and the model is rejected unless common shocks are included.

${ }^{21}$ To arrive at (15), first solve equations (6) and (7) to get reduced form equations for $i_{t}$ and $s_{t}$ as functions of $x_{t}$ and $z_{t}$. Next, project both sides of the equation on $x_{t}$. The left-hand side becomes the reduced form innovations $\nu_{t}^{i}$ and $\nu_{t}^{s}$ (see equation (8)), and the $x_{t}$ falls out of the right-hand side.

${ }^{22}$ See Rigobon (1999) for a discussion of the necessary rank condition and a more complete analysis of the impact of misspecifying the heterogeneity.
} 
written as a linear combination of the true covariance matrices, as follows:

$$
\Omega_{i, s}^{m i s j}=L^{m i s j} \cdot\left[\begin{array}{c}
\Omega_{i, s}^{r e g} 1 \\
\Omega_{i, s}^{r e g} 2 \\
\Omega_{i, s}^{r e g 3}
\end{array}\right]
$$

where the vector $L^{m i s j}$ is determined by the extent of the misspecification. If these misspecified regimes are used in (16) to solve for the parameters, the resulting system of equations will be a linear combination of the original system. Indeed, the following equations will hold:

$$
\left[\begin{array}{l}
\Omega_{i, s}^{m i s 1} \\
\Omega_{i, s}^{m i s 2} \\
\Omega_{i, s}^{m i s 3}
\end{array}\right]=\left[\begin{array}{l}
L^{m i s 1} \\
L^{m i s 2} \\
L^{m i s 3}
\end{array}\right] A^{-1} \Gamma\left[\begin{array}{c}
\sigma_{z}^{r e g 1} \\
\sigma_{z}^{r e g 2} \\
\sigma_{z}^{r e g 3}
\end{array}\right] \Gamma^{\prime} A^{\prime}-1+\left[\begin{array}{c}
L^{m i s 1} \\
L^{m i s 2} \\
L^{m i s 3}
\end{array}\right] A^{-1}\left[\begin{array}{c}
\Omega_{\varepsilon, \eta}^{r e g 1} \\
\Omega_{\varepsilon, \eta}^{r e g 2} \\
\Omega_{\varepsilon, \eta}^{r e g 3}
\end{array}\right] A^{\prime-1},
$$

which of course can be rewritten as

$$
\left[\begin{array}{l}
\Omega_{i, s}^{m i s 1} \\
\Omega_{i, s}^{m i s 2} \\
\Omega_{i, s}^{m i s 3}
\end{array}\right]=A^{-1} \Gamma\left[\begin{array}{c}
L^{m i s 1} \\
L^{m i s 2} \\
L^{m i s 3}
\end{array}\right]\left[\begin{array}{c}
\sigma_{z}^{r e g 1} \\
\sigma_{z}^{r e g 2} \\
\sigma_{z}^{r e g 3}
\end{array}\right] \Gamma^{\prime} A^{\prime}-1+A^{-1}\left[\begin{array}{c}
L^{m i s 1} \\
L^{m i s 2} \\
L^{m i s 3}
\end{array}\right]\left[\begin{array}{c}
\Omega_{\varepsilon, \eta}^{r e g 1} \\
\Omega_{\varepsilon, \eta}^{r e g 2} \\
\Omega_{\varepsilon, \eta}^{r e g 3}
\end{array}\right] A^{\prime-1}
$$

Note that using equation (17) rather than equation (16) generates the same solution for the parameters of the matrices $A$ and $\Gamma$. The misspecification of the heteroskedasticity regimes instead passes through entirely into the estimates of $\sigma_{z}$ and $\Omega_{\varepsilon, \eta}$, which will not equal their values under the true regimes. Thus, the misspecification of the regimes does not bias our estimates $(A$ and $\Gamma$ ) of the monetary policy response to the stock market.

This analysis holds as long as the misspecified system of equations continues to satisfy the equivalent rank condition that the original system satisfied. In that case, the misspecification of the regimes only reduces the efficiency of the estimates, as it averages out the differences across regimes that are the basis for identification. However, if the misspecification of the regimes is bad enough, the rank condition will be violated. Indeed, if the regimes are misspecified so much as to have equal weights of the true regimes, the $\Omega_{i, s}^{\text {misj }}$ may be proportional to one another. In that situation, equation (17) is a system of equations that is underidentified. ${ }^{23}$

To illustrate these points, consider a case in which the regimes are very poorly specified. In particular, we split the sample every three and six months and treat each as a separate regime. The results are shown in Table 6, which for brevity reports only the estimates obtained using all regimes. As is evident from the table, the estimates of the contemporaneous effect of stock markets on the interest rate are extremely noisy. This imprecision should be expected, as it is a direct

\footnotetext{
${ }^{23}$ This is easily testable. The equivalent approach in a linear system is to test the rank condition conditional on the order condition. In this case the heteroskedasticity provides the order condition, and the linear independence of the covariance matrices is the rank condition.
} 
consequence of the washing out of the regimes due to the misspecification.

Table 6: Estimates under Alternative Regimes

\begin{tabular}{lcc}
\hline \hline & $\begin{array}{c}\text { Random } \\
\text { 3-month } \\
\text { Regimes }\end{array}$ & $\begin{array}{c}\text { Random } \\
\text { 6-month } \\
\text { Regimes }\end{array}$ \\
\hline Mean of distribution & 0.033343 & 0.035966 \\
Std. dev. of distribution & 0.189599 & 0.21412 \\
Median of distribution & 0.044941 & 0.024758 \\
Mass below zero & $31.8 \%$ & $45.1 \%$ \\
\hline
\end{tabular}

Estimates based on all regimes.

If we stick to reasonable changes to the definitions of the regimes, though, the results found in section 4 are not strongly affected. To see this, we compute the estimates reducing the criteria for determining high volatility periods to half of a standard deviation (from the one standard deviation threshold used above) and then increasing it to two standard deviations. The point estimates, reported in Table 7, vary some but are largely similar to the results from section 4 . Indeed, one cannot statistically reject the hypothesis that they are equal to the previous results, with a significance level of $19.0 \%$ for the two standard deviation regimes and $9.7 \%$ for the one-half standard deviation regimes. Finally, the regimes could also be defined based on a regime-switching model estimated by maximum likelihood. We experimented with such a model and found that the estimated parameter was very similar to the ones reported earlier, which is perhaps not surprising given the results from Table 7 .

Table 7: Estimates under Alternative Regimes

\begin{tabular}{lcc}
\hline \hline & One-half & Two \\
& Std. dev. & Std. dev. \\
& Regimes & Regimes \\
\hline Mean of distribution & 0.009540 & 0.031816 \\
Std. dev. of distribution & 0.002871 & 0.009947 \\
Median of distribution & 0.009567 & 0.031308 \\
Mass below zero & $0.0 \%$ & $0.0 \%$ \\
\hline
\end{tabular}

Estimates based on all regimes.

\subsection{Changes in frequency}

Another important issue is whether the central bank's reaction to stock price movements depends on the frequency of the data. Indeed, one might expect that a rise in equity prices over the course 
of a day would prompt a different policy response than a same-sized rise that is sustained over a longer period. If daily movements in the stock market are more volatile (on an annualized basis) than weekly or monthly movements, as is the case in our sample, one might expect a more tempered response to higher frequency changes. ${ }^{24}$

To address this issue, we analyze the impact of changing the frequency of the exercise above from daily to weekly. The results, shown in Table 8, indicate that under the one-standard deviation threshold, the estimated response of monetary policy is very imprecise. One cannot even reject the hypothesis that the estimate equals zero. A possible explanation for this finding is that relying on lower frequency data reduces the heteroskedasticity in the data. Because there are fewer observations under the high variance regimes, it is more difficult to get precise estimates under this identification method.

Indeed, the precision of the estimate improves considerably if we reduce the threshold for the high variance regime to half a standard deviation. In that case, the coefficient is precisely estimated, with a point estimate of 0.023910 - somewhat larger than that found in the daily results. One can marginally reject the hypothesis that the weekly estimate is the same as the daily one, although the economic interpretation of the estimate is not that much different. According to the results, a $5 \%$ rise (fall) in the S\&P 500 over the course of a week causes the three-month Treasury bill rate to increase (decrease) by 12.0 basis points. Translating this into policy moves, the results suggest that a $5 \%$ rise in the S\&P 500 over a week increases the probability of a 25-basis point monetary policy tightening by $64 \% .{ }^{25}$ Moreover, as in the daily results, one cannot reject that the estimates are the same across other combinations of regimes, but the overidentification restrictions were rejected in the specification that excluded the common shocks.

Table 8: Estimates using Weekly Data

\begin{tabular}{lcc}
\hline \hline & One & One-half \\
& Std. dev. & Std. dev. \\
& Regimes & Regimes \\
\hline Mean of distribution & 0.014812 & 0.023910 \\
Standard deviation & 0.474815 & 0.011113 \\
Median of distribution & 0.024658 & 0.022638 \\
Mass below zero & $27.2 \%$ & $0.3 \%$ \\
\hline
\end{tabular}

Estimates based on all regimes.

\footnotetext{
${ }^{24}$ In our sample, daily stock price changes are slightly more volatile relative to weekly changes than would be expected if stock prices followed a random walk. The relative variance of stock market returns over different horizons has been explored in a number of papers, some of which find that changes over longer horizons are too volatile relative to daily changes to be consistent with a random walk. See, for example, Lo and MacKinley (1988).

${ }^{25}$ The impact on the three-month rate is 12.0 basis points, which translates roughly into a 15.9 basis point impact on the federal funds rate, or a $64 \%$ chance of a 25 basis point move in the federal funds rate.
} 


\subsection{Changes in the interest rate variable}

In all of the above results, inferences about future monetary policy decisions were made based on the behavior of the three-month Treasury bill. While the Treasury bill was once the most liquid security at short maturities, its liquidity has deteriorated notably over the sample. Much of the market activity at shorter maturities has shifted to other securities, including eurodollar deposits and eurodollar futures contracts. Thus, one could argue that the eurodollar rate would be a more appropriate instrument for measuring policy expectations in the latter part of the sample. We ran an alternative set of daily results replacing the three-month Treasury yield with the rate on the near-term eurodollar futures contract (the next contract to expire). The value of this contract is based on the three-month eurodollar rate at the time of expiration, which is always within three months (the contracts are quarterly). The results were very similar, indicating that the conclusions reached above are not importantly influenced by the choice of the interest rate variable.

\section{Conclusions}

This paper attempts to decompose daily and weekly movements in interest rates and stock prices into the endogenous responses to different types of shocks. To do so, we rely on an indentification technique based on the patterns of comovements that emerge when the variances of the shocks shift. By relying on heteroskedasticity to identify the system of equations, we are able to effectively measure the reaction of the short-term interest rate to the stock market, even when the stock market is endogenously reacting to the interest rate at the same time. The results suggest that stock market movements have a significant impact on short-term interest rates, driving them in the same direction as the change in stock prices.

We attribute this response to the anticipated reaction of monetary policy to the stock market. This interpretation should be taken a bit cautiously, however. The reason is that the results do not condition on the source of the movement in equity prices. Ideally, we would focus on exogenous shifts in equity prices, or ones that are independent of any factors that may also affect the outlook for monetary policy. But such movements, if they even exist, are difficult to identify. The empirical exercise does control for several types of shocks by including the major macroeconomic data releases in the specification. In addition, we include an unobserved shock in the specification that appears to capture changes in investor risk preferences. However, it is still possible that the remaining equity price movements are systematically driven by other factors, and thus the measured policy response could in part reflect the impact of those factors on the policy outlook.

Regardless of this consideration, the exercise provides an estimate of the magnitude of the response of short-term interest rates to a typical movement in stock prices. The results indicate that a $5 \%$ rise in stock prices over a day causes the perceived probability of a 25 -basis point interest rate hike to increase by a half. A similar-sized movement that takes place over a week has a slightly larger effect on anticipated policy actions. The magnitude of these responses is consistent with some 
rough calculations of the impact of stock price movements on aggregate demand, suggesting that policy makers are reacting to stock price movements to the extent warranted by their implications for the macroeconomy.

\section{References}

Bernanke, Ben and Mark Gertler, Monetary Policy and Asset Price Volatility, Economic Review (1999), Federal Reserve Bank of Kansas City, 17-51.

Bryant, Ralph C., Peter Hooper, and Catherine Mann, eds., Evaluating Policy Regimes: New Research in Empirical Macroeconomics, Brookings: Washington, D.C. (1993).

Cecchetti, Stephen G., Hans Genberg, John Lipsky, and Sushil Wadhwani, Asset Prices and Central Bank Policy, Geneva Reports on the World Economy, Centre for Economic Policy Research (2000).

Clarida, R., J. Gali, and M. Gertler, Monetary Policy Rules and Macroeconomic Stability: Evidence and Some Theory, Quarterly Journal of Economics 115 (2000), 147-180.

Judd, John P. and Glenn D. Rudebusch, Taylor's Rule and the Fed: 1970-1997, Economic Review 3 (1998), Federal Reserve Bank of San Francisco. 3-16.

Lo, Andrew W. and A. Craig MacKinlay, Stock Market Prices Do Not Follow Random Walks: Evidence from a Simple Specification Test, Review of Financial Studies 1 (1988), 41-66.

Poterba, James and Andrew Samwick, Stock Ownership Patterns, Stock Market Fluctuations, and Consumption, Brookings Papers on Economic Activity 2 (1995), 295-372.

Reifschneider, David, Robert Tetlow, and John Williams, Aggregate Disturbances, Monetary Policy, and the Macroeconomy: The FRB/US Perspective, Federal Reserve Bulletin 85 (1999), Federal Reserve Board of Governors, 1-19.

Rigobon, Roberto, Identification through Heteroskedasticity: The bivariate case, Mimeo (1999), Sloan School of Management, Massachusetts Institute of Technology.

Sack, Brian, Uncertainty, Learning, and Gradual Monetary Policy, Finance and Economic Discussion Series working paper no. 98-34 (1998), Federal Reserve Board of Governors.

Taylor, John B., Discretion versus Policy Rules in Practice, Carnegie-Rochester Conference Series on Public Policy 39 (1993), 195-214. 
Taylor, John B., ed., Monetary Policy Rules, National Bureau of Economic Research, Chicago: University of Chicago Press (1999). 


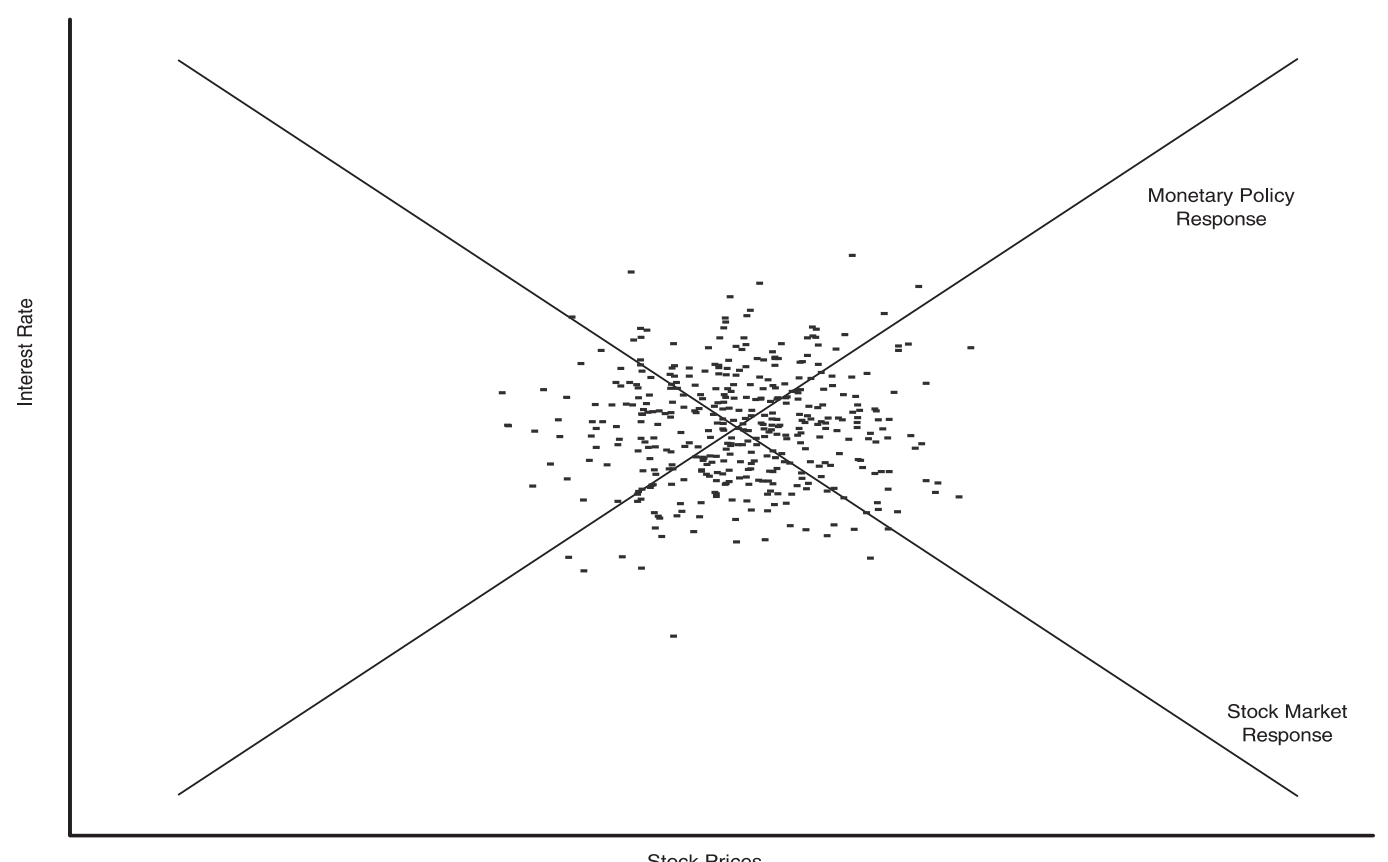

Figure 1: Joint Determination of Interest Rates and Stock Prices

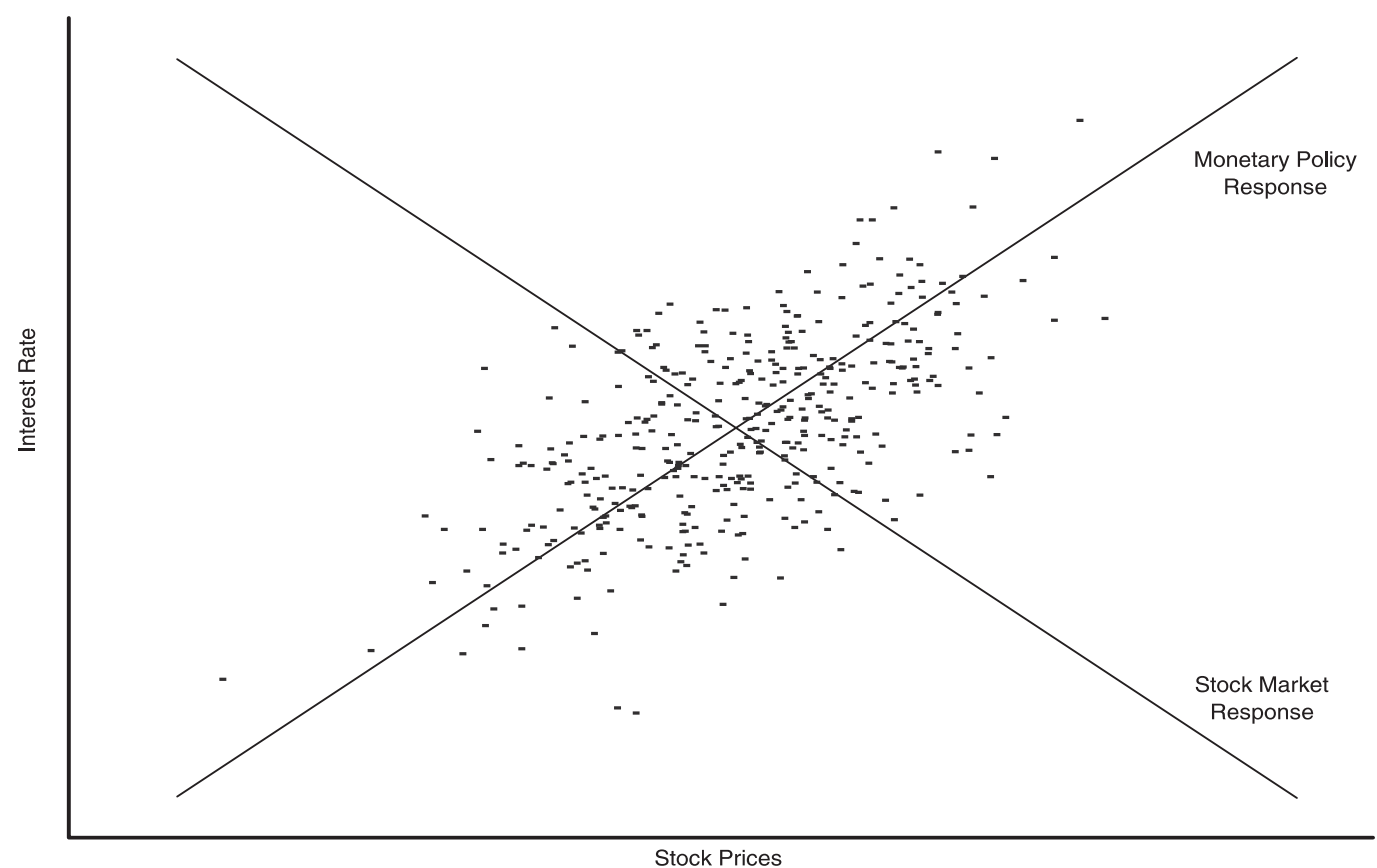

Figure 2: Periods of High Stock Market Volatility 


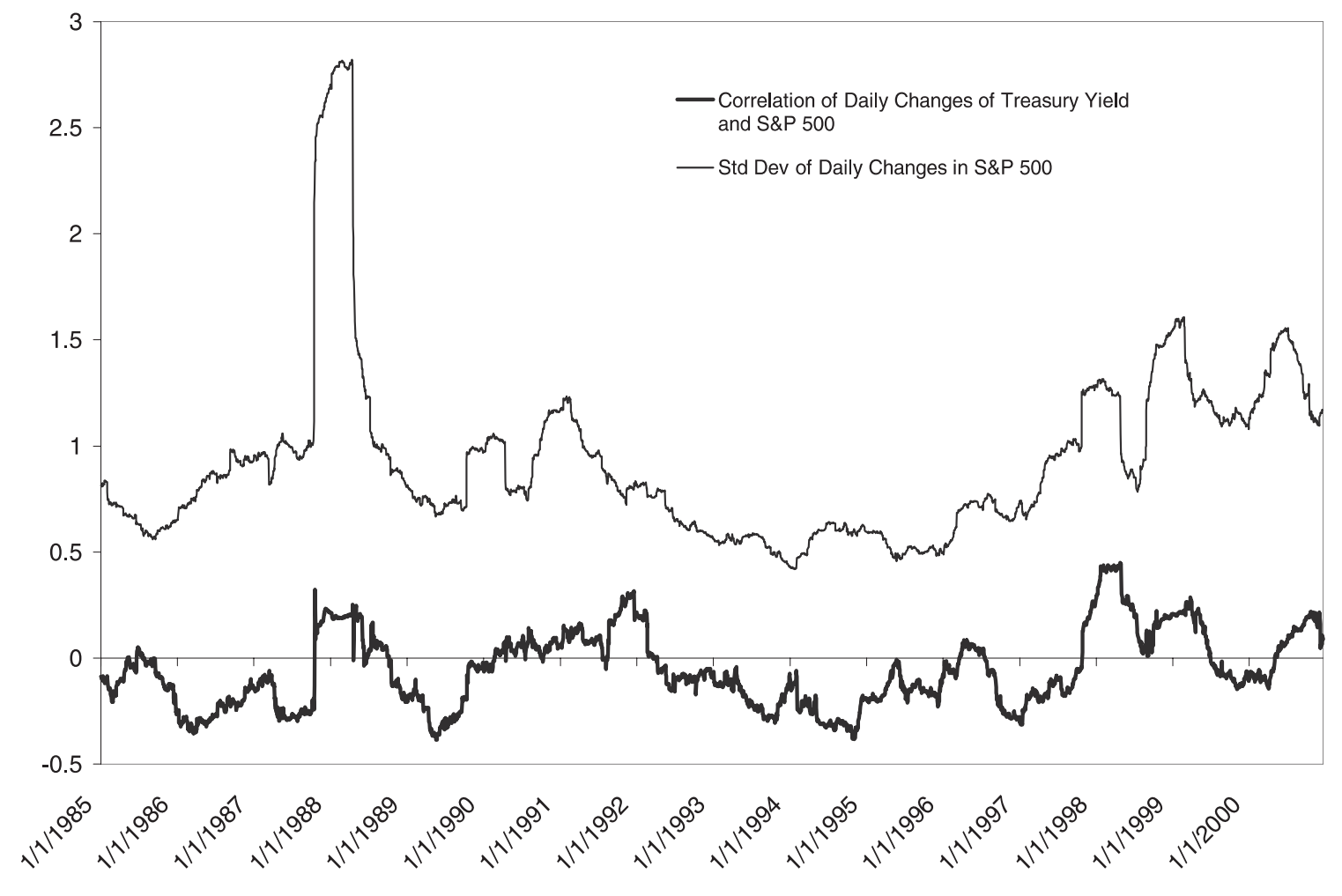

Figure 3: Comovements in Equity Prices and Interest Rates 

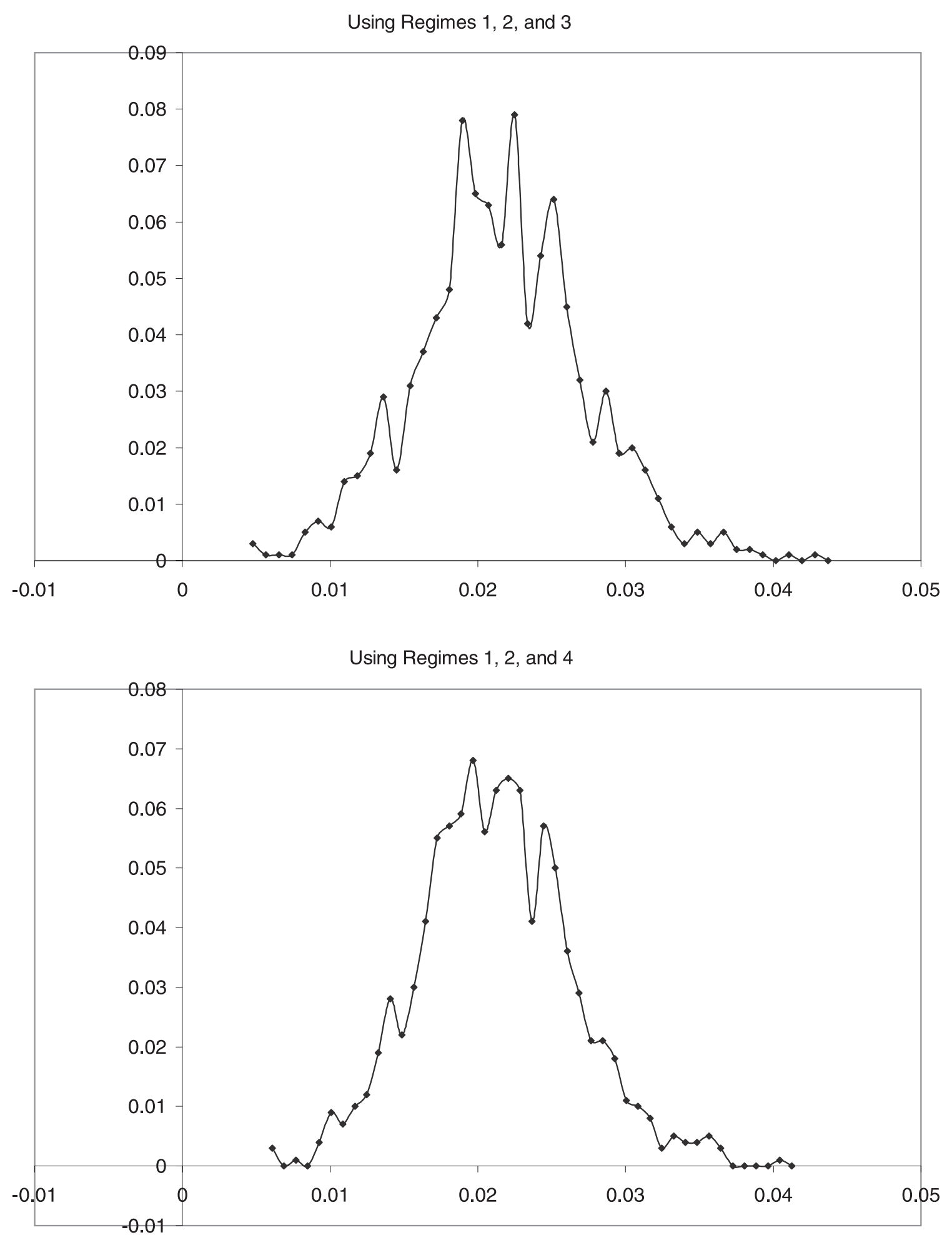

Figure 4: Distributions of Estimated Policy Response Coefficient: Regimes 1-2-3 and Regimes 1-2-4 


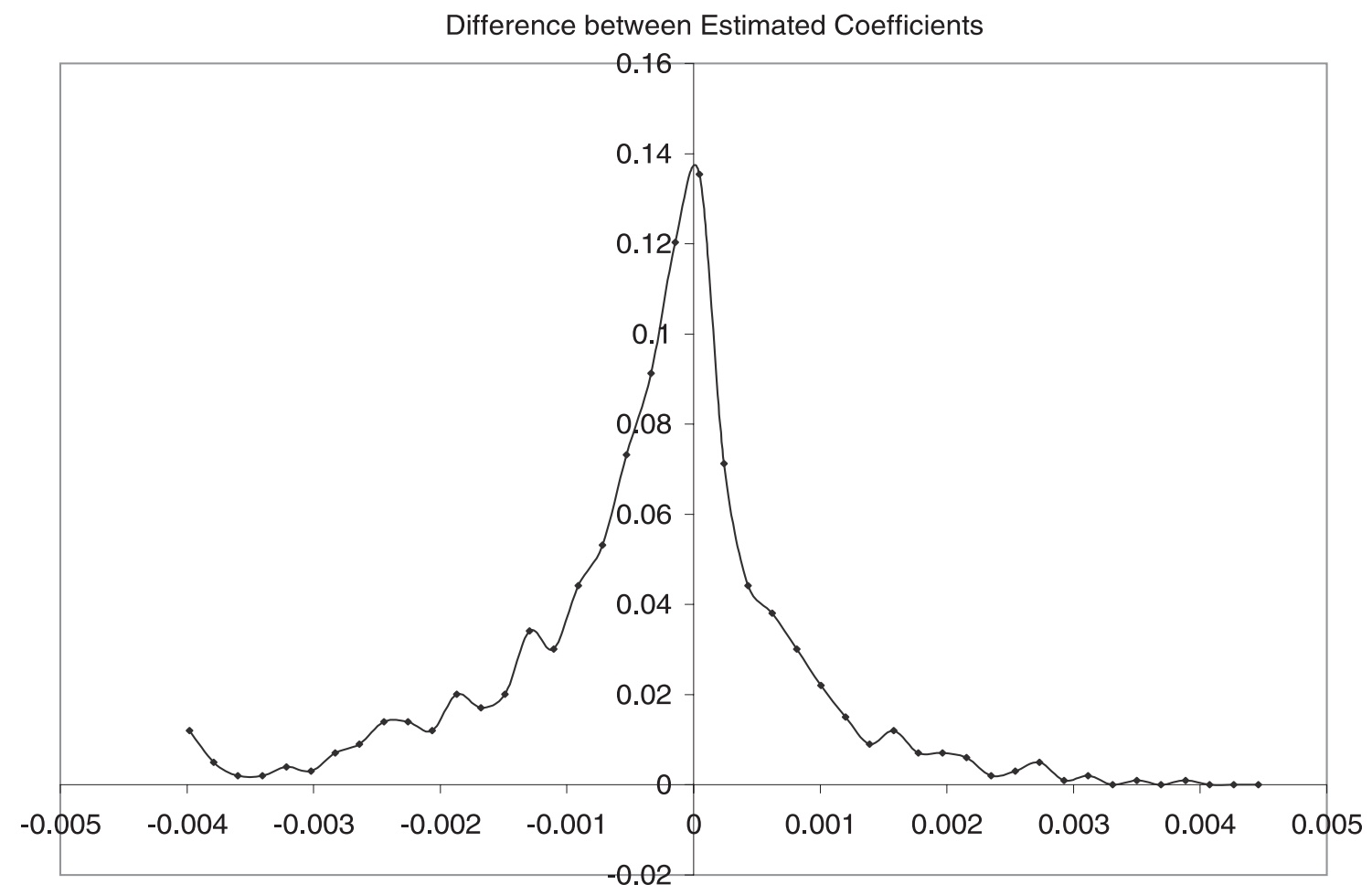

Figure 5: Test of Overidentifying Restrictions:

Regimes 1-2-3 versus Regimes 1-2-4 

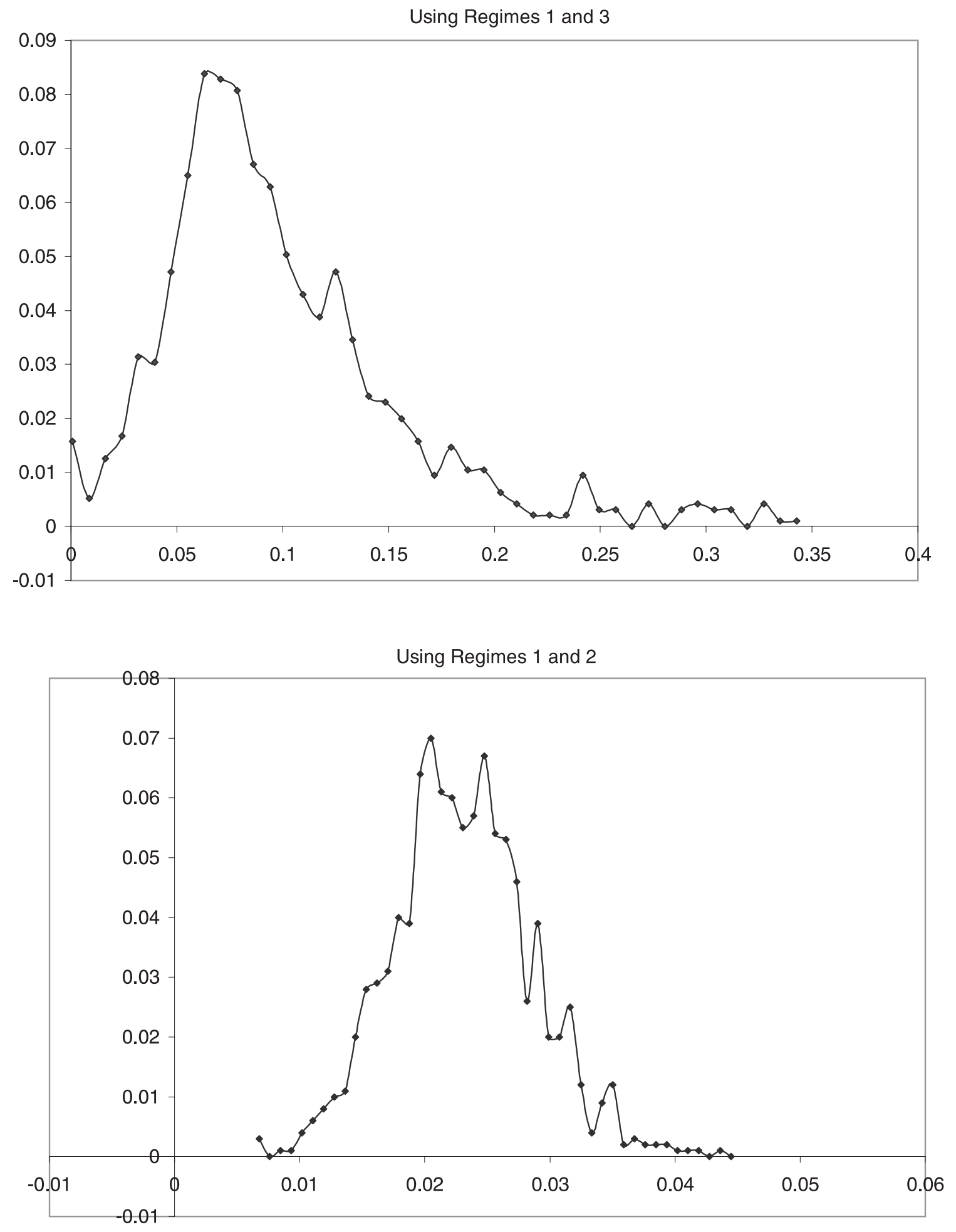

Figure 6: Distributions of Estimated Policy Response Coefficient without Common Shocks: Regimes 1-2 and Regimes 1-3 


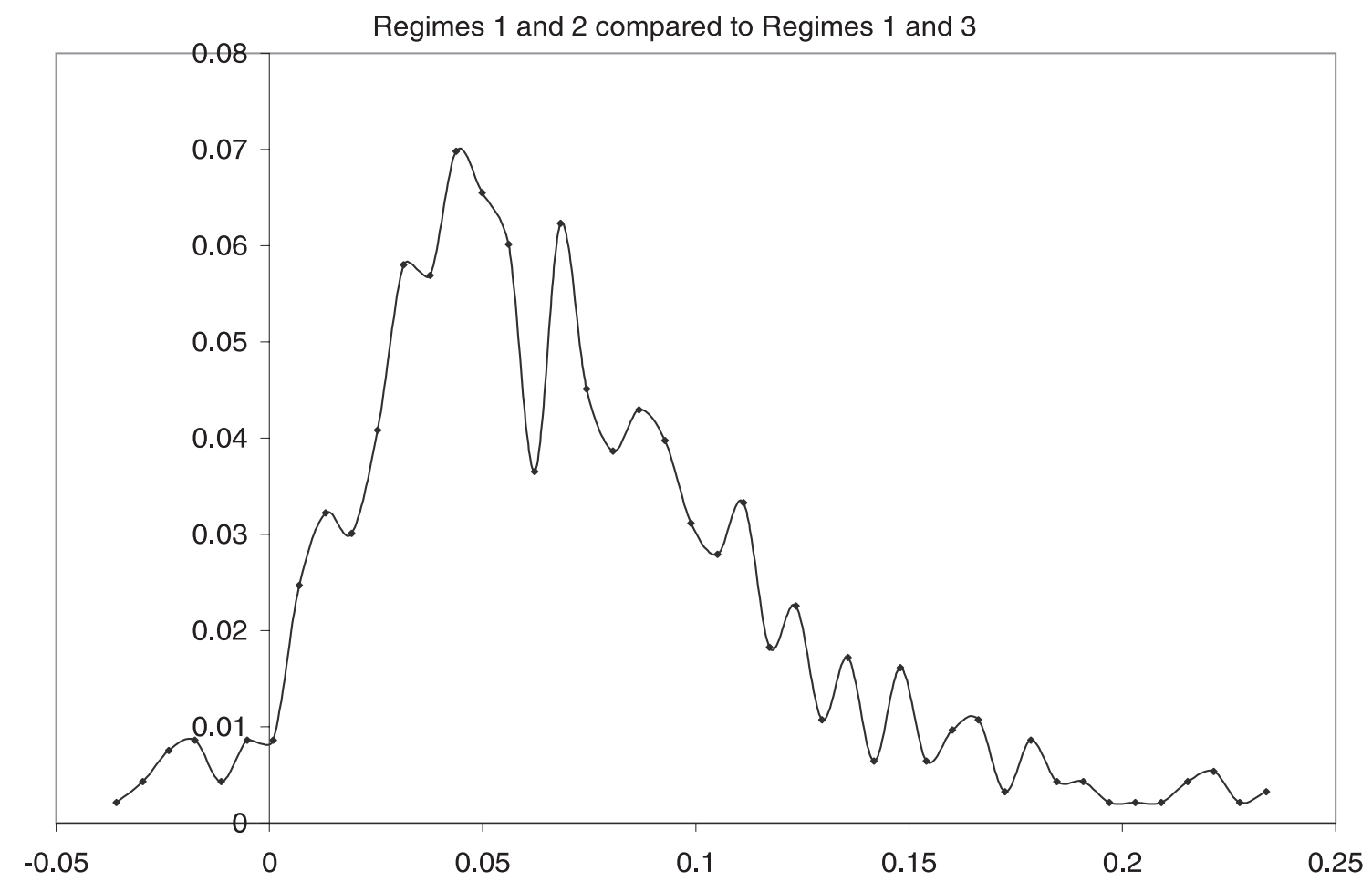

Figure 7: Test of Overidentifying Restrictions without Common Shocks:

Regimes 1-2 versus Regimes 1-3 